ORIGINAL ARTICLE

\title{
Caesarean section and gastrointestinal symptoms, atopic dermatitis, and sensitisation during the first year of life
}

\author{
B Laubereau, B Filipiak-Pittroff, A von Berg, A Grübl, D Reinhardt, H E Wichmann, S Koletzko, \\ for the GINI Study Group
}

Arch Dis Child 2004;89:993-997. doi: 10.1136/adc.2003.043265

See end of article for authors' affiliations

Correspondence to:

Dr S Koletzko, Kinderklinik

\& Kinderpoliklinik Dr. v.

Haunersches Kinderspital,

Ludwig-Maximilians-

University Munich,

Lindwurmstr. 4 D-80337

Munich, Germany;

sibylle.koletzko@med.

uni-muenchen.de

Accepted 2 February 2004
Aims: To investigate the effect of caesarean section on gastrointestinal symptoms, atopic dermatitis, and sensitisation to nutritional allergens in infants.

Methods: A total of 865 healthy full term neonates with parental history of allergy participating in the prospective German Infant Nutritional Intervention Program (GINI) were exclusively breast fed during the first four months of life and had a one year follow up. Data were obtained by follow up visits at age 1, 4, 8, and 12 months, weekly diaries for the first six months, and measurement of total and specific lgE at birth and 12 months.

Results: Infants born by caesarean section $(147 / 865,17 \%)$ had a greater risk of diarrhoea $\left(O R_{\text {adi }} 1.46\right.$, $95 \% \mathrm{Cl} 1.022$ to 2.10 ) and sensitisation to food allergens, both in adjusted (OR adj $2.06,95 \% \mathrm{Cl} 1.123$ to 3.80 ) and stratified analyses (by cord blood lgE). Caesarean delivery was not associated with colicky pain and atopic dermatitis.

Conclusion: Caesarean delivery might be a risk factor for diarrhoea and sensitisation in infants with family history of allergy. Further research in this area seems warranted as choosing caesarean section becomes increasingly popular.
1: $\mathrm{n}$ developed countries rising rates of caesarean section and the question of a woman's choice of elective caesarean are currently subject to a heated debate, both in scientific articles $^{12}$ and the lay media. Risks and benefits of this procedure for mother and child must be carefully considered, particularly for on demand procedures. Apart from morbidity and mortality associated with any major abdominal surgery there might also be postnatal adverse effects for the child due to bypassing "the natural way" of delivery. Currently alteration of the intestinal flora of infants born by caesarean section and possible consequences for the infant's health attract considerable scientific interest. It has been shown that bacterial colonisation of the gut in infants born by caesarean delivery differs from that in infants born by vaginal delivery; ${ }^{4}$ for example, a lack of Bacteroides spp, bifidobacteria, and lactobacilli has been shown in their faecal specimens. The clinical relevance of this finding is unclear. However, these bacteria are clearly identified as probiotics and have been used for the treatment and prevention of gastrointestinal infections during infancy. Addition of these probiotic strains to formula fed infants significantly reduced the risk of acquiring a diarrhoeal illness and for shedding of rotavirus. ${ }^{5}$ Therefore, infants born by caesarean section may have an increased risk for diarrhoea or other gastrointestinal symptoms.

It has been suggested that the delayed establishment of the normal intestinal flora and impairment of the gut barrier, which both play an important role in postnatal maturation of the immune system and development of oral tolerance, may lead to a higher risk of developing allergic diseases in later life. However, previous research in this subject produced conflicting results. ${ }^{6-8}$ The aim of this analysis was to investigate whether caesarean delivery was associated with gastrointestinal symptoms, atopic dermatitis, and sensitisation to nutritional allergens during infancy.

\section{METHODS}

\section{Study design and subjects}

We used data from a birth cohort of healthy full term neonates with a family history of allergy enrolled between 1995 and 1998 in two regions in Germany for the German Infant Nutritional Intervention Program (GINI). Newborns with severe congenital or metabolic diseases, or other medical conditions interfering with the study design, were excluded from enrolment. The study is described in detail elsewhere. ${ }^{9}$ Briefly this was a prospective randomised study to investigate the allergy preventive effect of three hydrolysed formulae compared to a conventional cows' milk formula. At birth all mothers were given uniform nutritional recommendations on feeding the child during the first year of life. ${ }^{10}$ For ethical reasons, study formulae were to be fed only when the recommended exclusive breast feeding for the first four months was not feasible. Follow up visits with structured interview and physical examination were scheduled for age 1 , 4,8 , and 12 months. During the first six months mothers filled in weekly diaries on feeding and health status of the child. Blood samples for total IgE were obtained at birth (cord blood (CB)), and for specific IgE at 12 months of age. The sera were kept at $-20^{\circ} \mathrm{C}$ until analysis. Contamination of cord blood by maternal blood was excluded by measurement of IgA levels in cord blood samples with detectable IgE levels $(\geqslant 0.35 \mathrm{kU} / \mathrm{l})$. This analysis is restricted to infants exclusively breast fed during the first four months of life with a one year follow up. Formula fed infants were excluded because the feeding regimen was heterogeneous and this group differed significantly from the exclusively breast fed group with respect to mode of delivery, compliance to the given feeding recommendations, and socioeconomic characteristics.

Abbreviations: $\mathrm{CB}$, cord blood; $\mathrm{Cl}$, confidence interval; $\mathrm{OR}$, odds ratio 


\section{Classification of exposure and outcomes Caesarean section}

Information on mode of delivery was copied by a physician from the child's medical check up chart during the interview at age 1 month. Answer categories "spontaneous delivery" and "obstetrical extraction" were combined into "no caesarean section".

\section{Gastrointestinal symptoms}

"Colicky pain" was based on parental reporting in both the interviews and the weekly diaries. It was assessed for the first four months only, as this was felt to be the clinically relevant period. "Diarrhoea" was based on parental reporting in the interviews up to age 4 months and 12 months respectively. Information from the diaries was not used as they were available for the first six months only.

\section{Atopic dermatitis}

Atopic dermatitis was defined using a computer algorithm ${ }^{9}$ based on (1) typical skin lesions assessed by the study physician; (2) reported itching and/or signs of scratching and/or reported treatment with steroids/oral antihistamines; and (3) reported duration of at least 14 days without treatment and/or chronically relapsing. Case definition required all three criteria.

\section{Atopic sensitisation to nutritional allergens}

The RAST technique was used according to the manufacturer's instructions (Pharmacia and Upjohn Diagnostics AB, Uppsala, Sweden). Specific IgE were tested at age 12 months for major cows' milk allergens (alpha-lactalbumin f76, betalactoglobulin $\mathrm{f77}$, casein $\mathrm{f78}$ ) and ovalbumin $\mathrm{fl}$ and soybean f14. Atopic sensitisation at age 12 months was defined as at least one specific IgE $\geqslant$ RAST class 1 (levels $\geqslant 0.35 \mathrm{kU} / \mathrm{l}$ ) if results for all five allergens were available.

\section{Statistical analysis}

Multiple logistic regression analyses were used to determine association of caesarean section with outcomes, adjusting for a fixed set of risk factors (sex, parental history of allergy, birth order, pet keeping). Further potential confounding factors (gestational age, cord blood IgE, maternal age at birth, birth weight, smoking before pregnancy, parental education) were included in the final model if the effect estimate of caesarean section on the outcome was changed by more than $10 \%$. Uniform models were chosen each for diarrhoea, colicky pain, and sensitisation at all time points. Results are presented as adjusted OR with 95\% CI. SAS for Windows (version 8.01, SAS Institute 1999-2000, Cary, NC) was used for all calculations. The study protocol was approved by the local ethic committees.

\section{RESULTS}

\section{Baseline characteristics}

Of 2252 infants included in the GINI study, 191 (9\%) discontinued the study within the first four months. Of the remaining 2061 infants, 889 were exclusively breast fed during the first four months of life; 865/889 (97\%) had a one year follow up and were included in our analysis. The rate of caesarean section was $17.0 \%$ (147/865). Pregnancy risk factors, as documented by the obstetrician in the child's medical check up chart, were equally distributed between the two groups with respect to mother's severe illnesses (heart, lung, etc), allergy, psychosocial stress, and history of complications in previous pregnancies. As expected, malposition of the fetus and history of previous caesarean deliveries were reported significantly more often in the caesarean section group $(7.5 \% \vee 0$ and $16.3 \% \vee 4.6 \%$ respectively). Reports of rhesus incompatibility, symptoms of gestosis, infections, and long term medication were negligibly rare in all mothers (data not shown). Table 1 shows baseline characteristics of the study population by mode of delivery. The two groups differ with respect to proportions of firstborns, older gestational age, CB-IgE availability and CB-IgE levels.

\section{Caesarean section and outcomes}

Table 2 presents the association between caesarean delivery and gastrointestinal symptoms, atopic dermatitis, and sensitisation during the first year of life. Colicky pain during the first four months of life was not associated with mode of delivery, if assessed by either interview (table 2) or by weekly diaries (data not shown). This is also true if frequency of episodes of colicky pain (at least three times in 16 weekly diaries: $24.5 \%$ in caesarean section group versus $29.0 \%$ in vaginally delivered infants, $\mathrm{p}=0.27$ ) or counts per month were compared (data not shown). In contrast, diarrhoea up to age 12 months was associated with caesarean delivery. Risk estimates levelled off with increasing age. Effects were more pronounced in the subgroups of infants with mucous and/or bloody diarrhoea (table 2).

Atopic dermatitis during the first 12 months of life was not associated with caesarean section. However, atopic sensitisation to nutritional allergens at age 12 months was positively associated. In our study population infants born by caesarean section more often had detectable cord blood IgE (table 1); therefore additional stratification by results of IgE analysis $(<0.35 \mathrm{kU} / \mathrm{l}$ versus $\geqslant 0.35 \mathrm{kU} / \mathrm{l})$ was performed. The positive association between mode of delivery and sensitisation to any of the five nutritional allergens persisted in the strata (crude OR for CB-IgE $<0.35 \mathrm{kU} / \mathrm{l}: 3.50,95 \%$ CI 1.2 to 10.5 ; and for CB-IgE $\geqslant 0.35 \mathrm{kU} / \mathrm{l}: 2.2,95 \%$ CI 0.66 to 7.2 ), although confidence intervals were wide due to small numbers in the strata.

\section{DISCUSSION}

In this cohort of 865 healthy neonates we found that infants born by caesarean section had a higher risk for diarrhoea and sensitisation to nutritional antigens during the first year of life compared to vaginally born infants.

\section{Caesarean section, gut flora, and development of the immune system}

Our results are in line with a current hypothesis that the gut flora very early in life plays an important role for the immune response $\mathrm{e}^{11}$ and that circumstances associated with caesarean section alter or delay "normal" colonisation of the gut micro flora of the infant. ${ }^{3}{ }^{1213}$ This alteration could be due to different factors. The colonisation of vaginally delivered newborns is influenced by the mother's vaginal, intestinal, and perianal flora, whereas infants delivered by caesarean section are colonised with bacteria from the hospital environment. Moreover in the latter group "rooming in" is less common and prophylactic use of perioperative antibiotics is highly recommended. ${ }^{14}$ Each factor by itself may adversely affect the development of the infant's gut flora.

Reports on the clinical significance of the microbiological findings in infants born by caesarean section are scarce and conflicting with respect to gastrointestinal symptoms. A study in 168 infants from the neonatal intensive care unit in Turku, Finland, reported caesarean section and prematurity to be significant risk factors for $C$ perfringens in stool, which was associated with the occurrence of gastrointestinal symptoms like flatulence, distended abdomen, diarrhoea, and blood in stool. ${ }^{15}$ In contrast, in 64 healthy term infants born at the same hospital no differences were found between infants born by caesarean section $(\mathrm{n}=30)$ and vaginally $(\mathrm{n}=34)$ with respect to flatulence, abdominal distension, 
Table 1 Characteristics of the study population $(n=865)$ by mode of delivery

\begin{tabular}{|c|c|c|c|c|c|}
\hline & \multicolumn{4}{|c|}{ Caesarean section } & \multirow[b]{3}{*}{ p value* } \\
\hline & \multicolumn{2}{|l|}{ Yes } & \multicolumn{2}{|l|}{ No } & \\
\hline & $\mathrm{n} / \mathrm{N}$ & $\%$ & $\mathrm{n} / \mathrm{N}$ & $\%$ & \\
\hline Female sex & $70 / 147$ & 47.6 & $363 / 718$ & 50.4 & 0.52 \\
\hline \multicolumn{6}{|l|}{ Birth weight (g) } \\
\hline $2500-2999$ & $17 / 147$ & 11.6 & $84 / 718$ & 11.7 & 0.91 \\
\hline $3000-3699$ & $82 / 147$ & 55.8 & $412 / 718$ & 57.4 & \\
\hline$\geqslant 3700$ & $48 / 147$ & 32.7 & $222 / 718$ & 30.9 & \\
\hline \multicolumn{6}{|l|}{ Birth length $(\mathrm{cm})$} \\
\hline$\leqslant 51$ & $49 / 147$ & 33.3 & $258 / 718$ & 35.9 & 0.70 \\
\hline $52-53$ & $49 / 147$ & 33.3 & $245 / 718$ & 34.1 & \\
\hline$>53$ & $49 / 147$ & 33.3 & $215 / 718$ & 29.9 & \\
\hline Head circumference $\geqslant 37 \mathrm{~cm}$ & $18 / 129$ & 14.0 & $73 / 640$ & 11.4 & 0.41 \\
\hline \multicolumn{6}{|l|}{ Gestational age (completed week) } \\
\hline$\leqslant 41$ & $134 / 147$ & 91.2 & $693 / 717$ & $96 . .6$ & 0.003 \\
\hline \multirow{2}{*}{\multicolumn{6}{|c|}{ Age mother at birth (y) }} \\
\hline & & & & & \\
\hline$<30$ & $32 / 146$ & 21.9 & $191 / 715$ & 26.7 & 0.16 \\
\hline $30-34$ & $77 / 146$ & 52.7 & $389 / 715$ & 54.1 & \\
\hline$>34$ & $37 / 146$ & 25.3 & $135 / 715$ & 18.9 & \\
\hline Birth order: firstborns & $100 / 146$ & 68.5 & $372 / 717$ & 51.9 & $<0.001$ \\
\hline Born at perinatal centre & $46 / 147$ & 31.3 & $204 / 718$ & 28.4 & 0.48 \\
\hline Cord blood available & $67 / 147$ & 45.6 & $488 / 718$ & 68.0 & $<0.001$ \\
\hline Cord blood total lgE $\geqslant 0.35 \mathrm{kU} / \mathrm{l}$ & $25 / 67$ & 37.3 & $115 / 488$ & 23.6 & 0.015 \\
\hline Maternal asthma & $22 / 147$ & 15.0 & $99 / 718$ & 13.8 & 0.71 \\
\hline Maternal history of allergy† & $104 / 147$ & 70.8 & $503 / 718$ & 70.1 & 0.87 \\
\hline Both parents history of allergyt & $50 / 147$ & 34.0 & $240 / 718$ & 33.4 & 0.89 \\
\hline \multicolumn{6}{|l|}{ Maternal smoking } \\
\hline Before pregnancy (yes) & $37 / 146$ & 25.3 & $132 / 713$ & 18.5 & 0.06 \\
\hline During pregnancy (yes) & $12 / 146$ & 8.2 & $62 / 714$ & 8.7 & 0.86 \\
\hline During first year of life (yes) & $10 / 145$ & 6.9 & $53 / 714$ & 7.4 & 0.82 \\
\hline Pets in household & $26 / 144$ & 18.1 & $112 / 706$ & 15.9 & 0.52 \\
\hline Parental school education $>12 y$ & $122 / 147$ & 83.0 & $561 / 717$ & 78.2 & 0.20 \\
\hline Rural place of residence & $50 / 145$ & 34.5 & $243 / 712$ & 34.1 & 0.94 \\
\hline
\end{tabular}

bowel habits, and colicky crying within the first two months of life in spite of differences found for the gut flora. ${ }^{3}$ These studies were both confined to a selected group of children from one hospital. It was shown previously that certain environmental circumstances may influence the development of the infant's gut flora. ${ }^{316}$ This unwanted effect of one

Table 2 Association between caesarean delivery and gastrointestinal symptoms, atopic dermatitis, and sensitisation in infants exclusively breast fed for four months

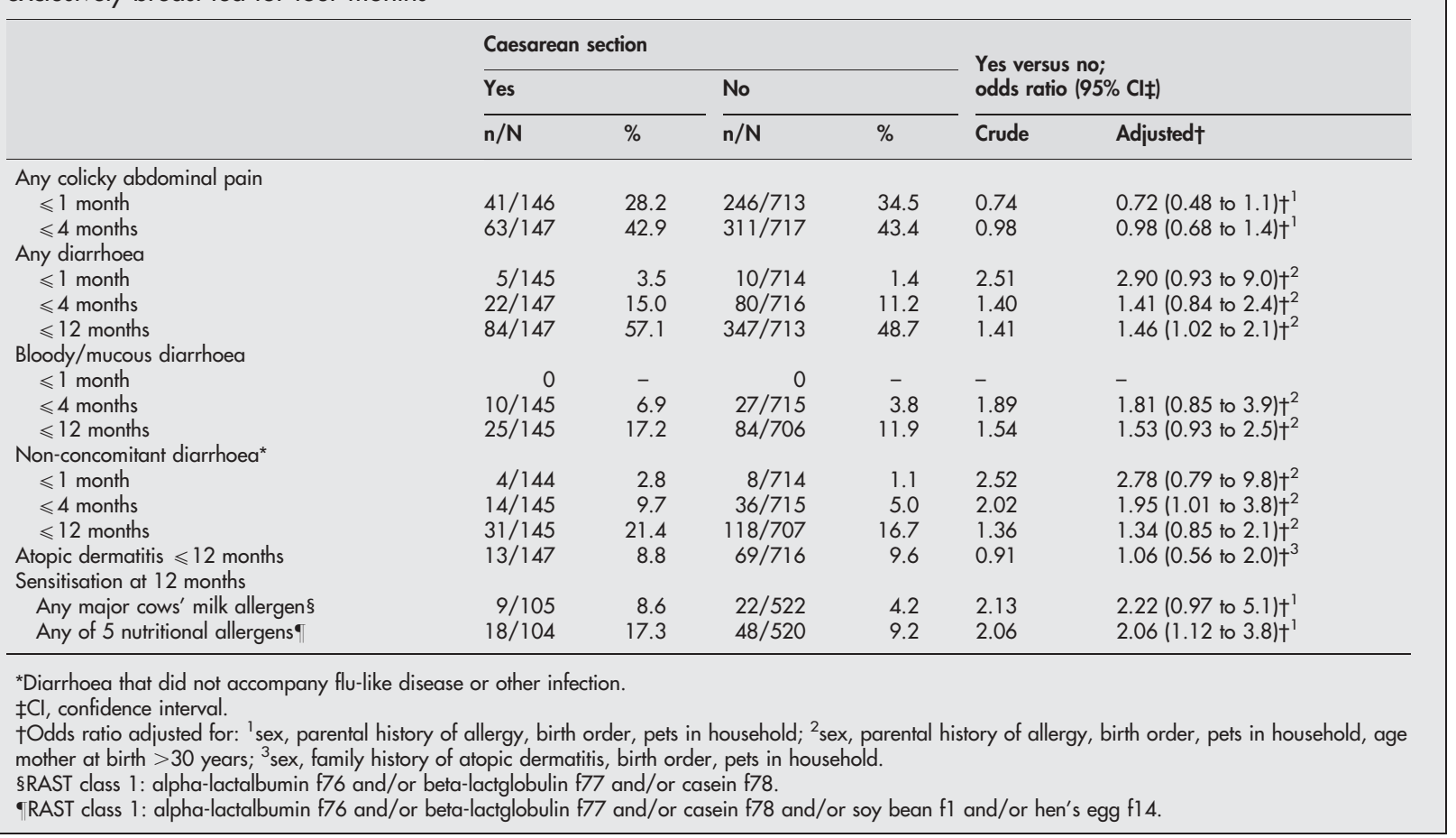


specific setting was avoided in our study by the large sample of children born in several hospitals in two regions of Germany. Adjustment for study area and perinatal centres did not change our results (data not shown).

\section{Characteristics of the study population}

Confounding by different health status at birth, gestational age, heredity of allergy, and different feeding patterns was minimised by choosing a homogeneous study population. High risk pregnancies leading to emergency caesarean sections were excluded. All infants had a positive family history for allergic diseases and had parents with similar educational level. Mothers were uniformly instructed to avoid feeding strong nutritional allergens during the first year of life. Formula fed infants differed significantly from exclusively breast fed infants with respect to mode of delivery, compliance to the given feeding recommendations, and socioeconomic characteristics (data not shown). The formula fed infants were excluded from the analysis because this group was heterogeneous when comparing the caesarean section born infants with the vaginally delivered infants with respect to many characteristics. Moreover we felt that early infant nutrition might strongly interfere with the outcomes. We considered it beyond the data to control for the impact of infant nutrition in this group because the type, the quantity, and the timing of first introduction of formula milk and of solid food varied considerably (data not shown).

\section{Diarrhoea}

It cannot be established whether the episodes of diarrhoea with mucous, sometime blood stained stools in our study population were of infectious origin, or whether they were caused by a mild allergic colitis, which we and others ${ }^{17}$ increasingly observe in exclusively breast fed infants. However, a recent study from Sweden reported a significant increase of hospital admissions for gastroenteritis in children born by caesarean section compared to children born by vaginal delivery, ${ }^{18}$ which is in agreement with our results.

\section{Sensitisation}

Apart from diarrhoea as a measure of short term effects of an abnormal gut flora we found a remarkably higher rate of sensitisation to nutritional allergens in infants born by caesarean section. Specific IgE to nutritional allergens, especially hen's egg, which was the main allergen in our study, has been shown to be positively associated with later sensitisation to aeroallergens, the development of asthma, and severity of atopic dermatitis. ${ }^{19}$ It is uncertain whether our findings also indicate a long term effect. The postnatal gut flora seems to be important for the development of oral tolerance and the immune response to allergens, ${ }^{11}{ }^{20}$ thus an abnormal colonisation might predispose to allergic manifestations later in life. ${ }^{13} 21-23$ The role of cord blood IgE as a predictor of later sensitisation is still under discussion. ${ }^{24} 25$ The fact that cord blood was missing more often after caesarean section was due to logistic reasons, which should not bias our results. However, to our surprise infants born by caesarean section had raised cord blood IgE levels more often than vaginally delivered infants. This finding, which could not be explained by parental or mother's history of asthma or other allergic diseases, smoking habits, or educational level, contradicts previous results of a large German birth cohort study. ${ }^{24}$ Contamination with maternal blood, which is a major concern, was excluded by non-detectable IgA levels. Older gestational age and birth order have been reported to have an influence on cord blood IgE, ${ }^{25}{ }^{26}$ and thus may have played a role. However, controlling for cord blood IgE did not change the risk estimate for caesarean section; neither did stratification by cord blood IgE status.

\section{Allergic diseases}

Several recent studies focused on the association between caesarean delivery and allergic diseases, mainly asthma. A positive association with asthma was reported in five studies, $^{6-81827}$ while no association was found in two. ${ }^{28} 29$ Atopic dermatitis was investigated in two studies ${ }^{67}$ and allergic rhinitis in four, ${ }^{6727} 29$ and no association was found for any of them. However, controlling for confounding factors such as prematurity, feeding pattern early in life, or allergic diseases in the parents was often poor. In our study we also did not find an association between caesarean section and atopic dermatitis $(\mathrm{AD})$ during the first year of life, which is the major period for clinical manifestation of AD. We could not investigate asthma and allergic rhinitis, as the children were too young for these outcomes. As the birth cohort is followed, we will be able to extend our analysis on these outcomes in the future.

\section{Conclusion}

We found an association between caesarean delivery and diarrhoea and sensitisation in infants with a family history of allergy. Further research in this subject seems warranted as choosing caesarean section becomes increasingly popular.

\section{ACKNOWLEDGEMENTS}

We would especially like to thank all children and families for participation in the study, the obstetric units to allow the recruitment procedure, and the GINI team for excellent work.

\section{Authors' affiliations}

B Laubereau, B Filipiak-Pittroff, H E Wichmann, GSF-National Research Centre for Environment and Health, Institute of Epidemiology, Neuherberg, Germany

A von Berg, Marien-Hospital Wesel, Department of Pediatrics, Wesel, Germany

A Grübl, Technical University of Munich, Department of Pediatrics, Munich, Germany

D Reinhardt, S Koletzko, Ludwig-Maximilians-University, Department of Pediatrics, Munich, Germany

The GINI study (German Infant Nutritional Intervention Study) was supported by the Federal Ministry for Education, Science, Research and Technology, Grant No. 01 EE 94014. The data analysis of this study was supported by Institute Danone Foundation and the Child Health Foundation ("Stiftung Kindergesundheit").

Gini Study Group: Wesel: D Berdel, A von Berg, B Albrecht, A Baumgart, Ch Bollrath, S Büttner, S Diekamp, T Jakob, K Klemke, S Kurpiun, T Müller-Wening, A Varhelyi, C Zorn; LMU Munich: D Reinhardt, S Koletzko, B Bäumler-Merl, R Göhlert, I Jesch, M Koch, T Saverwald, C Sönnichsen, C Tasch, M Waag, H Weigand, D Mühlbaver; TU Munich: CP Baver, A Grübl, P Bartels, I Brockow, A Fischer, U Hoffmann, R Mayrl, K Negele, E-M Schill, B Wolf; GSF Institute for Epidemiology Neuherberg: HE Wichmann, A Schoetzau, $M$ Engl, B Filipiak-Pittroff, K Franke, U Gehring, K Honig-Blum, G Kruse, M Popescu, A Sindl, A Zirngibl

\section{REFERENCES}

1 O'Connell MP, Lindow W. Caesarean section controversy. Further research is needed on why rates of caesarean section are increasing. BMJ 2000;320:1074.

2 Wagner M. Choosing caesarean section. Lancet 2000;356:1677-80.

3 Gronlund $M M$, Lehtonen OP, Eerola $\mathrm{E}$, et al. Fecal microflora in healthy infants born by different methods of delivery: permanent changes in intestinal flora after cesarean delivery. J Pediatr Gastroenterol Nutr 1999;28:19-25.

4 Bennet R, Nord CE. Development of the faecal anaerobic microflora after caesarean section and treatment with antibiotics in newborn infants. Infection 1987; 15:332-6.

5 Saavedra JM, Bauman NA, Oung I, et al. Feeding of Bifidobacterium bifidum and Streptococcus thermophilus to infants in hospital for prevention of diarrhoea and shedding of rotavirus. Lancet 1994;344:1046-9.

6 Kero J, Gissler M, Gronlund MM, et al. Mode of delivery and asthma-is there a connection? Pediatr Res 2002;52:6-11.

7 McKeever TM, Lewis SA, Smith C, et al. Mode of delivery and risk of developing allergic disease. J Allergy Clin Immunol 2002;109:800-2.

8 Xu B, Pekkanen J, Hartikainen AL, et al. Caesarean section and risk of asthma and allergy in adulthood. J Allergy Clin Immunol 2001;107:732-3. 
9 von Berg A, Koletzko S, Gruebl A, et al. The effect of hydrolyzed cow's milk formula for allergy prevention in the first year of life: The German Infant Nutritional Intervention Study (GINI), a randomized double-blind trial. J Allergy Clin Immunol 2003;1 11:533-40.

10 Schoetzau A, Gehring U, Franke K, et al. Maternal compliance with nutritional recommendations in an allergy preventive programme. Arch Dis Child 2002;86: 180-4.

11 Sudo N, Sawamura S, Tanaka K, et al. The requirement of intestinal bacterial flora for the development of an lgE production system fully susceptible to oral tolerance induction. J Immunol 1997;159:1739-45.

12 Kirjavainen PV, Gibson GR. Healthy gut microflora and allergy: factors influencing development of the microbiota. Ann Med 1999;31:288-92.

13 Bjorksten B, Naaber $\mathrm{P}$, Sepp E, et al. The intestinal microflora in allergic Estonian and Swedish 2-year-old children. Clin Exp Allergy 1999;29:342-6.

14 Smaill F, Hofmeyr GJ. Antibiotic prophylaxis for cesarean section. Cochrane Database Syst Rev, 2002;CD000933.

15 Ahtonen P, Lehtonen OP, Kero P, et al. Clostridium perfringens in stool, intrapartum antibiotics and gastrointestinal signs in a neonatal intensive care unit. Acta Paediatr 1994:83:389-90.

16 Orrhage K, Nord CE. Factors controlling the bacterial colonization of the intestine in breastfed infants. Acta Paediatr Suppl 1999;88:47-57.

17 Anveden-Hertzberg L, Finkel Y, Sandstedt B, et al. Proctocolitis in exclusively breast-fed infants. Eur J Pediatr 1996:155:464-7.

18 Hakansson S, Kallen K. Caesarean section increases the risk of hospital care in childhood for asthma and gastroenteritis. Clin Exp Allergy 2003;33:757-64.

19 Illi S, von Mutius E, Lau S, et al. The pattern of atopic sensitization is associated with the development of asthma in childhood. J Allergy Clin Immunol 2001;108:709-14.
20 Gronlund MM, Arvilommi H, Kero $\mathrm{P}$, et al. Importance of intestinal colonisation in the maturation of humoral immunity in early infancy: a prospective follow up study of healthy infants aged 0-6 months. Arch Dis Child Fetal Neonatal Ed 2000;83:F186-92.

21 Biorksten B. The intrauterine and postnatal environments. J Allergy Clin Immunol 1999; 104:1119-27.

22 Biorksten B, Sepp E, Julge K, et al. Allergy development and the intestinal microflora during the first year of life. J Allergy Clin Immunol $2001 ; 108: 516-20$.

23 Kalliomaki M, Kirjavainen $\mathrm{P}$, Eerola $\mathrm{E}$, et al. Distinct patterns of neonatal gut microflora in infants in whom atopy was and was not developing. J Allergy Clin Immunol 2001;107:129-34.

24 Bergmann RL, Schulz J, Gunther S, et al. Determinants of cord-blood lgE concentrations in 6401 German neonates. Allergy 1995;50:65-71.

25 Eiriksson TH, Sigurgeirsson B, Ardal B, et al. Cord blood lgE levels are influenced by gestational age but do not predict allergic manifestations in infants. Pediatr Allergy Immunol 1994;5:5-10.

26 Karmaus W, Arshad H, Mattes J. Does the sibling effect have its origin in utero? Investigating birth order, cord blood immunoglobulin $\mathrm{E}$ concentration, and allergic sensitization at 4 years. Am J Epidemiol 2001;154:909-15.

27 Bager P, Melbye M, Rostgaard K, et al. Mode of delivery and risk of allergic rhinitis and asthma. J Allergy Clin Immunol 2003;111:51-6.

28 Annesi-Maesano I, Moreau D, Strachan D. In utero and perinatal complications preceding asthma. Allergy 2001;56:491-7.

29 Nafstad P, Magnus P, Jaakkola JJ. Risk of childhood asthma and allergic rhinitis in relation to pregnancy complications. J Allergy Clin Immunol 2000; 106:867-73.

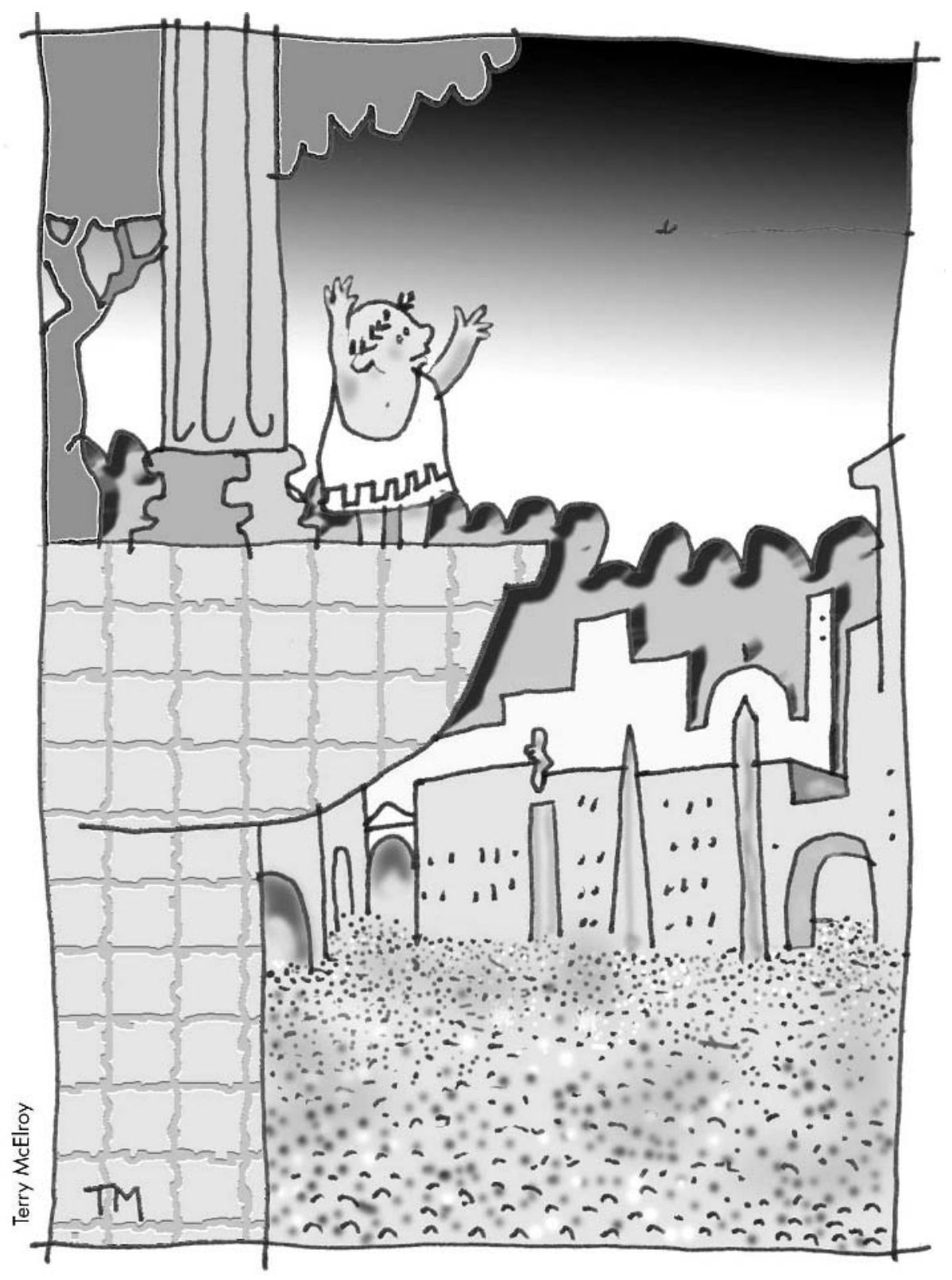

